\title{
The Impact of Implementing the International Baccalaureate Primary Years Programme on Students' Self-efficacy Beliefs
}

\author{
Nevine El Souefi \\ Chief Executive Officer - Edupedia, Cairo, Egypt \\ Received December 8, 2020; Revised February 18, 2021; Accepted March 12, 2021
}

\begin{abstract}
Cite This Paper in the following Citation Styles
(a): [1] Nevine El Souefi, "The Impact of Implementing the International Baccalaureate Primary Years Programme on Students' Self-efficacy Beliefs," Universal Journal of Educational Research, Vol. 9, No. 3, pp. 606 - 620, 2021. DOI: 10.13189/ujer.2021.090320.
\end{abstract}

(b): Nevine El Souefi (2021). The Impact of Implementing the International Baccalaureate Primary Years Programme on Students' Self-efficacy Beliefs. Universal Journal of Educational Research, 9(3), 606 - 620.601 : 10.13189/ujer.2021.090320.

Copyright $\subset 2021$ by authors, all rights reserved. Authors agree that this article remains permanently open access under the terms of the Creative Commons Attribution License 4.0 International License

\begin{abstract}
The holistic approach of the International Baccalaureate (IB) programmes encourages students to become active, compassionate and life-long learners. The IB defines its international education programmes through a learner profile that consists of ten attributes; inquirers, knowledgeable, thinkers, communicators, principled, open-minded, caring, risk-takers, balanced, and reflective [33]. For students to reach all IB learners profile attributes they need to be self-regulated learners [36]. Students' self-efficacy beliefs are one of the components of self-regulated learning [15], and a key component of social cognitive theory [4]. Self-efficacy beliefs also contribute to students' academic achievements, motivations and learning [41]. The Primary Years Programme (PYP) is the IB curriculum framework for children aged 3-11 that offers an inquiry-based, transdisciplinary curriculum framework building conceptual understandings. By learning through inquiry PYP students use their initiatives and take responsibility for their own learning [33]. This approach in learning claims to build students' self-efficacy that contributes to self-regulation [36]. The paper presents an inductive qualitative study capturing the impact of implementing the IB PYP on students' self-efficacy beliefs. The study was conducted in an IBPYP candidate school in Alexandria (second largest city in Egypt), which had been implementing the PYP for two years. Data was collected through four focus group discussions from different stakeholders; leaders, teachers, students and parents. The study findings revealed the perspectives of the different stakeholders about the reasons behind students' self-efficacy beliefs. The study resulted in an interpretation
\end{abstract}

of a spiral for the different aspects of PYP pedagogy that relate and integrate to support students' self-efficacy beliefs. The study resulted also in identifying specific aspects in school culture that support students' self-efficacy beliefs. The findings of the study will be beneficial to students, teachers, leaders, syllabus designers, and policy makers in IBPYP schools.

Keywords Self-efficacy, Egypt, Self Regulation, International Baccalaureate, Primary Years Programme

\section{Introduction}

According to [41], students' self-efficacy beliefs are a key component of social cognitive theory as it contributes to the students' academic achievements, motivations and learning. Reference [4] sees beliefs of personal efficacy the central to mechanisms of agency that affects their functioning in life. "Unless people believe they can produce desired effects by their actions, they have little incentive to act. Efficacy belief, therefore, is a major basis of action. People guide their lives by their beliefs of personal efficacy." (p. 2)

Reference [1] introduced the concept of perceived self-efficacy that affect how people motivate themselves and how they feel, think and act. According to $[28,29]$ self-efficacy is not about learning strategies that would help you succeed, but it is about how to keep trying when you fail. It is the base of motivation, well-being, and 
personal accomplishment.

Reference [2] defined self-efficacy as, "People's judgments of their capabilities to organize and execute courses of action required to attain designated types of performances" (p. 391). This definition has two important aspects. The first that it is a belief, which means the judgment of one's capacities is not necessarily true or accurate [41]. Reference [2] argues that the personal judgment that is slightly more than one's actual capacity can increase effort and persistence. The second is that it refers to a specific goal of a specific type of performance. This aspect differentiates self-efficacy from other terms of self-belief; like self-concept, and self-esteem. What the three terms have in common is that they all involve beliefs about perceived abilities. However, each has a specific different meaning [12].

For [41], self-esteem is about self-worth judgements. It does not involve cognitive judgements like self-efficacy. It is more about emotional response to self. Reference [19] explains this difference by;

"Self-efficacy is concerned with judgments of personal capability, whereas self-esteem is concerned with judgments of self-worth. People may judge them- selves inefficacious in a given activity without any loss of self-esteem, if they do not invest their self-worth in that activity." (p.88).

According to [4], perceived self-efficacy can predict the achievements and the goals one can reach, while self-esteem neither influences personal goals nor academic performance. Reference [38] findings in his study supported [4] views. He investigated the difference between self-efficacy and self-esteem in predicting personal goals and academic performance and in being influenced by them. He found that self-efficacy was a much higher predictor and more strongly affected by personal goals and performance than self-esteem. He supports the notion that "the more task-specific the measure of confidence, the better will be the prediction of subsequent goal and performance." (p.725).

Reference [17] defines self-esteem as, "an individual's sense of value or self-worth, or the extent to which people value, appreciate or like themselves." (p.249). They found significant correlation between self-esteem and self-efficacy measures. Results confirmed Bandura's findings that self-esteem follows perceived self-efficacy expectations. However, they also found that self-esteem can cause changes in self-efficacy. Reference [13] highlighted that self-efficacy is influenced by cognitive judgements of the person to his abilities, whereas cognitive judgements are influenced by self-esteem. They concluded that self-esteem affects how individuals maintain positive thoughts about themselves after failure, which affects self-efficacy. "although self-efficacy derives from sources that are based on performance, self-esteem is proposed to moderate the accessibility of retrieving performance accomplishments from memory following failure." (p.5). This is supported by [39] views that high self-esteem helps individuals to reject negative events and focus on positive points, while low self-esteem internalizes failure.

Self-concept is a long-term general self-assessment [12]. According to [37] "it has an influence on, but is distinct from, self-efficacy. Self-concept is a more expansive, global notion of one's personal essence, including thoughts, feelings and values" (p.2). For [4,5], self-concept is a source for self-efficacy. Self-efficacy is a result of the confidence people have in their own abilities [27]. Reference [34] sees "Self-efficacy is concerned not with that I believe I will do but with what I believe I can do." (p.4).

Self-efficacy beliefs were seen by [15] as a component of the Self-regulation model. Self-regulation refers to the degree to which students are metacognitively, motivationally, and behaviorally proactive and responsible participants in their own learning process [15]. The model explains how students go about a task using different components of self-regulation. The model consists of three phases. The first phase is called forethought phase where students analyse the task by setting goals and strategically plan. In this phase they use their self-motivational beliefs of; self-efficacy, outcome expectations, and task interest. The second phase is the performance phase where learners engage in the task. The third phase is the self-reflection phase, where students self-monitor outcomes and reflect on their progress. The self-reactions and judgements formed in this phase will impact the self-efficacy of the first phase for the coming task. According to [15] "Empirical evidence shows that this multi-level model of the development of self- regulation enables learners to learn master tasks and experience greater motivation." (p.8)

Self-regulatory strategies have been linked to higher self-efficacy in studies in the fields of education and psychology $[35,40,20]$. The cycle of self-regulatory learning enhances both students' learning and their perception of self-efficacy [16].

The International Baccalaureate Organisation [32]

"aims to develop internationally minded people who, recognizing their common humanity and shared guardianship of the planet, help to create a better and more peaceful world. IB learners strive to be: Inquirers, Knowledgeable, Thinkers, Communicators, Principled, Open-minded, Caring, Risk-takers, Balanced, and Reflective." (p.4-5)

The IB identifies specific standards and practices for the PYP to regulator factors that are driven by beliefs and values embodied in the profile contributing to overall success of the programme. The curriculum framework of the PYP prescribes five essential elements; knowledge, concepts, skills, attitudes, and action each help to frame the school's curriculum. The PYP curriculum model adopts the constructivist approach of how children learn. Through inquiry strategies students make meaning of the world around them; constructing, testing, and confirming or revising their personal models. Confidence is one of the attitudes that are promoted in PYP classes [32]. 


\section{Sources of Self-efficacy and PYP}

According to [6], people's beliefs about their efficacy can be modified and developed. Reference [3] identified sources of self-efficacy beliefs to be; mastery experiences, experiences provided by social models, social persuasion, and person's emotional status/moods. Reference [29] argues that mastery experience should be authentic, i.e. it is real and unique, not created and biased. Reference [28,29] see teachers can improve students' self-efficacy beliefs by boosting their competence and confidence through advancing their academic skills and behavious and changing discouraging factors in the environment. He also claims that encouraging students to be proactive in their own development gives them the positive feeling of control over their thoughts, feelings and actions [28].

According to [11], "Self-regulation theory contends that these effective learning behaviors can be taught irrespective of socioeconomic disadvantage, learner limitations, or other environmental factors." (p.6). As [14] pointed out that self-regulation is now seen as context-specific processes that schools can select from according to their needs and not a fixed characteristic of students. Reference [29] sees that self-efficacy habits are formed in early age encouraged by parents and influential teachers.

Reference [11] investigated students' self-efficacy beliefs and self-regulation in three PYP schools in the United States. The study had three phases each with different aims and results. Phase 1 aim was to document and understand self-regulation in PYP classes. This phase highlighted processes that enhanced [15] self-regulation model. Results highlighted inquiry-based learning and students being risk-takers as developing self-initiated learning. The learner profile was used by teachers to develop self-regulation using it for goal setting, feedback and monitoring the process. Group work and peer teaching were identified as aspects that develop students' self-efficacy beliefs. Phase 2 aim was to assess practices that lead to self-regulatory competences for students and teachers and how they influence self-efficacy for learning. This phase provided evidence of the correlation between self-efficacy and self-regulation, that mastery experience is the best predictor of self-efficacy, that social persuasion is a strong predictor of self-efficacy. Phase 3 examined best practices that foster high self-regulatory. This phase identified practices developing self-regulation and self-efficacy to be; Goal setting, enhancing motivation, collaborative learning, conceptual understanding, curriculum, reflection and celebrating growth.

The study ended by recommending seven principles for elementary education that enhances self-regulation; learning environments allowing students to own their learning, opportunities for reflection and collaboration, cooperation among students and teachers, use authentic tasks and problems, opportunities to practice ways of thinking and learning, scaffolding to support student learning, and create a culture of learning and respect for others. They also concluded that "The manner in which IB teachers are trained to develop inquiries and to challenge students are certainly influential to the development of student self-efficacy beliefs and students' use of selfregulatory learning practices." (P. 8)

Reference [18] assessed the interrelationship of PYP students' perceived responsibility for learning, self-efficacy, and sources of self-efficacy. Results conformed [2] sources of self-efficacy, however, the study found Social persuasions in the form of demonstration of skill with directed feedback to be the most influence on self-efficacy beliefs in contrast with [2] that mastery experience is the most influential source of self-efficacy. In this study mastery experience was equal to vicarious experience in predicting students' self- efficacy. The study also found that self-efficacy increased as students progressed through the grades in PYP. This is supported by [27] findings that children's self-efficacy increases as they learn and develop skills throughout the school years.

\section{Research Questions}

Teaching and learning in a PYP class move through an inquiry cycle. Through the inquiry cycle students are asks to accomplish challenging tasks like; investigating, making connections, taking action, or reflecting on action. According to the [32], "PYP schools ensure that the learning is engaging, relevant, challenging and significant." (P.5). The study aims to identify the impact of implementing PYP on self-efficacy beliefs to accomplish PYP tasks, identifying what aspects of the PYP build self-efficacy beliefs.

The following research questions were set to capture the impact of implementing the PYP on students' self-efficacy beliefs to accomplish PYP tasks.

1. Do learners demonstrate signs of self-efficacy beliefs to accomplish PYP tasks?

2. What aspects lead to learners' self-efficacy beliefs to accomplish PYP tasks from different stakeholder perspective?

3. How much do aspects that lead to learners' self-efficacy beliefs from stakeholder's perspective, match components of the PYP?

Data collected from focus group discussions focused on the first two questions to explore if students demonstrate signs of self-efficacy beliefs to accomplish PYP tasks, and the reasons behind those beliefs from the perspectives of different stakeholders, teachers, leaders, students, parents. Data collected to answer the third question was through document review matching findings of the second question to components of the PYP found in PYP documents.

\section{Methodology}

Data was collected through four focus group discussions for different stakeholders; leaders, teachers, students, and parents. The procedure for conducting the focus group discussions was done in the following procedure: 
- The school was approached through a meeting with the principle explaining exactly what the research will be about and the possible benefits.

- An email was sent to the principle of the school with a consent form to be signed (Appendix 1)

- A permission was given to the researcher by the principle to send out by mail an information sheet with a consent form to teachers and parents explaining exactly what the research is about and asking for volunteering teachers, students and parents.

- Some teachers, parents and parents of some students volunteered to participate in the study and signed the consent form.

- All focus group discussions were conducted at the school premises on the same day.

- The researcher was the one leading the discussion by initiating non-structured questions.

A constructivist worldview of the study with a qualitative research method was adopted. The interpretation and analysis are based on what is found in the qualitative data from informants' language and concepts. The research questions mentioned guided the methods used in the study.

The school chosen for the study is a PYP candidate school situated in Alexandria Egypt that has been implementing the PYP for two years. The study was done in April 2018. The school started from the pre-K year (age 3 ) up to grade 5. The choice of participants was random. All participants volunteered for the study. Participants were:

1. Two Leaders: The principle of the school and the PYP coordinator.

2. Seven teachers from different grades; Four homeroom teachers from different grades, one French teacher, one Arabic teacher, and one Math teacher.

3. Three parents from different grades.

4. Five students from different grades.

Data was collected through four focus group discussions; parents, teachers, leaders, and students, taking place at the school premises. The focus group discussions were conducted by the researcher asking questions to encourage discussions and expressions of different opinions. The data collected through focus group discussions answered the first and second research questions. The third research question was explored through document review of IBPYP documents.

The study took an interpretative stance with an exploratory design to examine themes and patterns immerging in the data collected from the focus group discussion. Therefore, non-structured questions were used in the focus group discussion that allowed participants a space to express their own ideas and opinions and allowed participants to engage in dynamic interactions with each other leading to shared or collective construction of meaning (Barbour, 2008). As the study was based on participants perspective, the non-structured focus group discussions empowered participants and decreased the researcher's control over the discussion $[25,26]$

\section{Data Analysis and Representation}

According to [43], qualitative analysis is "working with data, organising it, breaking it into manageable units, synthesising it, searching for patterns, discovering what is important and what is to be learned, and deciding what you will tell others" (p. 54). An open exploration to whatever the data brings was adopted. According to [45], "Thematic analysis involves the searching across a data set... to find repeated patterns of meaning" (p.11). Data from focus group discussions was analysed to answer the first and second research questions. Following [45] phases for data analysis, the data analysis methods for the study went into the following stages:

- The oral data was transcribed into a written document to be able to code it.

- Initially the data was coded to identify the source as follows;

- Leaders took initials; The principle $\mathrm{P}$, and the Coordinator $\mathrm{C}$

- The four homeroom teachers' codes were; HT1, HT2, HT3, HT4. Codes for the French, Arabic and Math teachers were; FT, AT, MT.

- $\quad$ Parents' codes were; P1, P2, P3.

- $\quad$ Students codes were; S1, S2, S3, S4, S5.

- Identifying common general themes was done by first reading all the data more than once to make sense of it and find the overall meaning.

- Patterns from participants' quotes were detected to shape common themes. According to [8], 'the themes and the sub-themes are the product of a thorough reading and re-reading of the transcripts or field notes that make up the data' (p. 579)

- Themes detected for questions 1 and question 2 were analyzed separately as follows:

For question 1: Do learners demonstrate signs of self-efficacy beliefs to accomplish PYP tasks?

To find the answer of this question from the focus groups data, themes looking for specific signs of self-efficacy beliefs to accomplish PYP tasks were guided by the following questions:

1. Do they believe that they have several solutions to any situation?

2. Do they believe that they can solve any difficult problem if they try hard enough?

3. Do they believe that they can deal with any unexpected events calmly?

4. Do they think that they can find their way to accomplish goals?

Those questions are based on [7] guide for constructing self-efficacy scales (2006), and adapted from [44]

Generalized Self-Efficacy scale, and [19] The Structure of Children's Perceived Self-Efficacy.

For question 2: What aspects lead to learners' self-efficacy beliefs from different stakeholder perspective? 
An open exploration to whatever the data brings was adopted. The following themes were detected from the data analysis:

Table 1. Themes detected from data answering Research question 2 What aspects lead to learners' self-efficacy beliefs from differen stakeholder perspective?

\begin{tabular}{|c|c|c|}
\hline $\begin{array}{c}\text { Main } \\
\text { themes }\end{array}$ & Sub-themes & Preceptive \\
\hline \multirow{6}{*}{$\begin{array}{c}\text { PYP } \\
\text { Pedagogy }\end{array}$} & Inquiry Strategies & \multirow{6}{*}{$\begin{array}{c}\text { Common } \\
\text { perspective } \\
\text { between all } \\
\text { stakeholders; } \\
\text { Leaders, } \\
\text { Teachers, } \\
\text { Students and } \\
\text { Parents }\end{array}$} \\
\hline & Students leading the learning process & \\
\hline & $\begin{array}{c}\text { build knowledge and conceptual } \\
\text { understandings }\end{array}$ & \\
\hline & Application in real life situations & \\
\hline & Students' Attitudes and Skills & \\
\hline & Reflection & \\
\hline \multirow{4}{*}{$\begin{array}{l}\text { School } \\
\text { Culture }\end{array}$} & $\begin{array}{c}\text { Homogenous learning community } \\
\text { Modeling the learner's profile }\end{array}$ & $\begin{array}{c}\text { Leaders' } \\
\text { perspective }\end{array}$ \\
\hline & Trust \& Respect & $\begin{array}{c}\text { Teachers } \\
\text { Perspective }\end{array}$ \\
\hline & Stress free & $\begin{array}{c}\text { Students' } \\
\text { perspective }\end{array}$ \\
\hline & Motivation & $\begin{array}{c}\text { Parents } \\
\text { Preceptive }\end{array}$ \\
\hline
\end{tabular}

For question 3: How much do aspects, that lead to learners' self-efficacy beliefs from stakeholder's perspective, match components of the PYP?

This question was explored through document review by analyzing IBPYP requirements. Tables matching the themes found from analyzing the second research question with IBPYP requirements in its documents were set to interpret the answer.

\section{Results}

Findings of the study handle each research question separately as follows:

\section{Research Question (1): Do learners demonstrate signs of self-efficacy beliefs to accomplish PYP tasks?}

The data collected indicated that all stakeholders can identify signs for the four questions (areas) of self-efficacy beliefs to accomplish PYP tasks.

The following table represents number of answers for every question and some examples of quotes found from four focus group discussions with different stakeholders; leaders, teachers, students, and parents, to answer the four questions that were designed to detect signs of self-efficacy beliefs. 
Table 2. Number of quotes with some examples collected from data answering Research question 1: Do learners in PYP classes demonstrate signs of self-efficacy beliefs from different stakeholders' perspective?

\begin{tabular}{|c|c|c|c|c|c|}
\hline & Leaders & Parents & Students & Teachers & $\begin{array}{c}\text { No of } \\
\text { answers }\end{array}$ \\
\hline $\begin{array}{l}\text { 1.Do they } \\
\text { believe that } \\
\text { they have } \\
\text { several } \\
\text { solutions to } \\
\text { any situation } \\
\text { they meet } \\
\text { while } \\
\text { working? }\end{array}$ & $\begin{array}{c}\text { "he knows the problem, he can mention his } \\
\text { problem ......... he can reflect wisely" PR } \\
\text { "they said they are going to change the } \\
\text { plan I said OK do that" C } \\
\text { "when they do mistakes as normal children } \\
\text { they can reflect on their mistakes and do } \\
\text { not it again" PR } \\
\text { "how they analyze the world, they question } \\
\text { everything........,the always think about } \\
\text { why is it like this. " C } \\
\text { "so they go with different question to find } \\
\text { the answers, each student finds the answer } \\
\text { he needs" PR }\end{array}$ & $\begin{array}{c}\text { "They have confidence that they understand } \\
\text { what they are doing .......... if something } \\
\text { went wrong they can fix it" PI } \\
\text { "He thinks about everything and asks ....if I } \\
\text { do not know the answer, he says I am going } \\
\text { to search for it .... this sometimes led him to } \\
\text { bigger ideas" P3 } \\
\text { "She is always motivated to produce a good } \\
\text { product" P2 } \\
\text { "the challenges they solve while working } \\
\text { gave them the confidence to face society } \\
\text { outside school" P1 }\end{array}$ & $\begin{array}{c}\text { "because I did } \\
\text { something wrong so I } \\
\text { want to make another } \\
\text { one." S } 2\end{array}$ & $\begin{array}{l}\text { "they started putting the shapes together and they said } \\
\text { miss we created a home" HRT2 } \\
\text { "they are not waiting for me to tell them this is wrong, } \\
\text { they became aware how to deal with each other" HRT1 } \\
\text { "why don't we use this in another way, they think in } \\
\text { different ways to get information" HRT2 } \\
\text { "They know how to do things on their own and they } \\
\text { know what they want, this appears a lot in their work" } \\
\text { HRT3 } \\
\text { "they have no problem to ask or give input." HRT4 } \\
\text { "he does not give an answer ...... he gives the answer } \\
\text { and then he starts to explain and tell ushow he got the } \\
\text { answer ........ they are capable now to prove what they } \\
\text { are saying" HRT1 } \\
\text { "when she recognized that she modeled in the wrong } \\
\text { way.... she reconsidered and start to model in the right } \\
\text { way." MT } \\
\text { "Sometimes they surprise me ..... I do not tell them the } \\
\text { information, they find it out themselves" FT }\end{array}$ & $\begin{array}{c}18 \\
\text { Answers } \\
\text { For Q1 }\end{array}$ \\
\hline $\begin{array}{l}\text { 2. Do they } \\
\text { believe they } \\
\text { can solve any } \\
\text { difficult } \\
\text { problem if they } \\
\text { try hard } \\
\text { enough? }\end{array}$ & $\begin{array}{c}\text { "This mean he is confident he is not afraid } \\
\text { that he made a mistake" C } \\
\text { "he took an action a now he is reflecting } \\
\text { and he changes this choice next time and } \\
\text { maybe he will act in a different way } \\
\text { because he knows the cause behind this" C } \\
\text { "they do whatever they need for what they } \\
\text { are learning" PR. }\end{array}$ & $\begin{array}{l}\text { "When I was trying to help him he told me: I } \\
\text { will search for it first and I will know what } \\
\text { to do"P3 } \\
\text { "She is always searching for something, } \\
\text { even things that she is not asked to do" P2 } \\
\text { "He thinks of solution for problems, he } \\
\text { understands the idea of impact, he was } \\
\text { telling me; why are we doing this, we want } \\
\text { our country to be clean" PI }\end{array}$ & $\begin{array}{l}\text { "if I made a mistake...,I } \\
\text { can just revise" } S 4 \\
\\
\text { "I am not scared when I } \\
\text { am working and I try .... } \\
\text { and if I did it wrong ... I } \\
\text { am not sad or mad ...,it } \\
\text { is ok ..... and I will do it } \\
\text { next time better." S3 }\end{array}$ & $\begin{array}{l}\text { "when they know that this is not the right answer ... } \\
\text { they start from the beginning." MT } \\
\text { "He said I want to do it again" AT } \\
\text { "they ask questions about everything around them even } \\
\text { if that is not what we are talking about" HRT2 } \\
\text { "They became better in taking decisions ....... they } \\
\text { know why they choose something and what they will } \\
\text { achieve" HRT }\end{array}$ & $\begin{array}{c}12 \\
\text { Answers } \\
\text { For Q2 }\end{array}$ \\
\hline
\end{tabular}


Table 2. Continued

\begin{tabular}{|c|c|c|c|c|c|}
\hline & Leaders & Parents & Students & Teachers & $\begin{array}{c}\text { No of } \\
\text { answers }\end{array}$ \\
\hline $\begin{array}{l}\text { 3. Do they } \\
\text { believe that } \\
\text { they can deal } \\
\text { with any } \\
\text { unexpected } \\
\text { events calmly? }\end{array}$ & $\begin{array}{c}\text { "they have self-regulation ..... they make the } \\
\text { right decision" PR } \\
\text { "he reflected that he knows well that when he } \\
\text { got angry, he cauld not control his temper.... } \\
\text { this time but he is going take care of this" PR } \\
\text { "they believe they have to make the right } \\
\text { decision ..... they have to solve the situation or } \\
\text { the problem they are facing" C }\end{array}$ & "He is not afraid of trying" $P 3$ & $\begin{array}{l}\text { "I need to look at it in the future and } \\
\text { see how I will do things and how it } \\
\text { will turn out to be."S5 } \\
\text { "all what we learn help me think } \\
\text { again and see what I have wrong” S2. } \\
\text { "the teacher tells us try again ...... } \\
\text { and I try again" S1 }\end{array}$ & $\begin{array}{l}\text { "they don't care if they asked a wrong question } \\
\text { or say something silly .... they all just smile and } \\
\text { play." HRT4 } \\
\text { "they can try new things ... they are risk takers", } \\
\text { HRT3 }\end{array}$ & $\begin{array}{c}9 \\
\text { Answers } \\
\text { For Q3 }\end{array}$ \\
\hline $\begin{array}{l}\text { 4. Do they } \\
\text { think that they } \\
\text { can find their } \\
\text { way to } \\
\text { accomplish } \\
\text { goals? }\end{array}$ & $\begin{array}{l}\text { "they feel responsible about whatever they are } \\
\text { doing" C } \\
\text { "They are very independent, they take their own } \\
\text { decisions and responsibilities about what they } \\
\text { are doing" PR } \\
\text { "He knows what he did and he can reflect" PR } \\
\text { when the students know the basic information } \\
\text { and facts and have the knowledge and } \\
\text { understand he believes he can apply this in } \\
\text { different situation" C } \\
\text { you always decide for us, we want to decide now, } \\
\text { we want to organize a party" C } \\
\text { They have ... this sense of ownership and } \\
\text { leading the learning process C } \\
\text { they do ask for trips for themselves to go and } \\
\text { explore.PR }\end{array}$ & $\begin{array}{l}\text { "When he wants to know } \\
\text { something, he knows how to } \\
\text { reach it and he knows how to } \\
\text { reason it out in his mind" P3 } \\
\text { "They go into the YouTube } \\
\text { and decide to design things. } \\
\text { Once they did a play dough } \\
\text { from a video they saw" P2 } \\
\text { "I feel he knows what he } \\
\text { wants, what he wants to know, } \\
\text { what he wants to reach, and } \\
\text { he knows how to reach it." P1 } \\
\text { "They are thinking all the time } \\
\text { of problems that they are } \\
\text { working on at the school" P3 }\end{array}$ & $\begin{array}{l}\text { "sometimes I do mistakes but not a } \\
\text { lot,.... and that is good.” S2 } \\
\text { "I feel like I am better at school” S1. } \\
\text { "the important thing is how we see } \\
\text { ourselves ... marks on work are } \\
\text { just .... like mark on a paper that is } \\
\text { all." S2 } \\
\text { "I feel I am doing well at school .... a } \\
\text { lot ..... I just feel it" S3 } \\
\text { "I like my class because I love to } \\
\text { learn" S1 }\end{array}$ & $\begin{array}{c}\text { "they show lots of confidence in show and } \\
\text { tell ...... they want to present their own work } \\
\text { "HRT2 } \\
\text { "they are very independent generally while they } \\
\text { are working" FT } \\
\text { "they became better at taking decisions ....... } \\
\text { skills, taking initiatives" HRT1 } \\
\text { "they are independent and they are very } \\
\text { self-aware" HRT4 } \\
\text { "We had a presenter yesterday ...... they felt that } \\
\text { they didn't reach the information they wanted } \\
\text { they started to ask questions... ..... they can ask } \\
\text { questions they want" HRT3 } \\
\text { they think in different ways to get up } \\
\text { information" HRT2 }\end{array}$ & $\begin{array}{c}22 \\
\text { Answers } \\
\text { For Q4 }\end{array}$ \\
\hline $\begin{array}{c}\text { Number of } \\
\text { answers }\end{array}$ & $\begin{array}{c}18 \text { answers } \\
\text { Answers by Leaders }\end{array}$ & $\begin{array}{c}12 \text { answers } \\
\text { Answers by Parents }\end{array}$ & $\begin{array}{c}10 \text { answers } \\
\text { Answers by Students }\end{array}$ & $\begin{array}{c}21 \text { answers } \\
\text { Answers by Teachers }\end{array}$ & $\begin{array}{l}61 \text { Total } \\
\text { answers }\end{array}$ \\
\hline
\end{tabular}


Research Question (2): What aspects lead to learners' self-efficacy beliefs from different stakeholders' perspective?

From the careful reading of the data two main themes were detected affecting self-efficacy beliefs from different stakeholders' perspectives:

\section{Specific aspects of Pedagogy:}

All stakeholders had common perspectives of the pedagogy that affect self-efficacy to be; Inquiry Strategies, Students leading the learning process, Students' conceptual understandings, Students' Attitudes and Skills, Application in real life situations, and Reflection. By exploring the aspects of pedagogy affecting self-efficacy, it was inferred that they all affect self-efficacy directly, as well as affecting each other forming a spiral that can, but not necessary go in the following order;

Students use Inquiry Strategies $\rightarrow$ Students lead the learning process $\rightarrow$ Students build their own knowledge and conceptual understandings $\rightarrow$ Students are able to Apply learning in real life situations $\rightarrow$ Students build Attitudes and Skills $\rightarrow$ Students Reflect on their actions

\section{All five elements of PYP $\rightarrow$ self-efficacy beliefs}

The coordinator saw that all the five PYP elements lead to student's self-efficacy.

"I do believe that, the five elements together form this impact that the pieces of the puzzle that forms the whole picture at the end" - C - Leaders focus group

"the skills that they do go through and the attitudes and then developing actions so the 5 elements together make the whole picture, so I believe yes the 5 elements they complete each other C - Leaders focus group

\section{Students use Inquiry Strategies $\rightarrow$ Self-efficacy beliefs}

The coordinator highlighted inquiry as a key. "I believe that inquiry is key." - C - Leaders focus group

Parents also noticed how experiencing success with inquiry can directly lead to self-efficacy beliefs.

"when she asks to go on google to research something and she finds it, this affects her character. She is more confident" P2 - Parents' focus group

\section{Students use Inquiry Strategies $\rightarrow$ Students lead the} learning process

The PYP coordinator emphasized the idea that inquiry puts the students in the central of learning that leads to students leading the learning process.

"inquiry let the students be the central of learning- " $C$

- Leaders focus group

The students clarified how they lead the learning process when put in the center of learning.

"we felt free when we did this activity, the teacher told us to feel free, to do whatever you want. If you want to cut the lungs, cut it but stay safe." S3 - Students' focus group

"we were asking her like what is inside. she didn't tell us but she said I don't know; you find out what is in the tube." S2-Students' focus group

\section{Students lead the learning process $\rightarrow$ Self-efficacy beliefs}

The coordinator saw that leading the learning process forms a sense of ownership that makes student confident.

"the sense of ownership and leading the learning process makes students confident"- C-Leaders focus group

\section{Students lead the learning process $\rightarrow$ Students build Attitudes and Skills}

Teachers identified how opened inquiry leads to thinking skills specifically creativity.

"When we introduce things in an opened way ....... a lot of creativity comes out" HT4 - Teachers' focus group

One of the parents concluded the relation between inquiry and self-efficacy beliefs by noticing her son's questioning skills.

"He forms so many questions all the time... for example, this starts once we go into the car going anywhere.... This cannot happen except with acquired skills and self-confidence"- P3 - Parents' focus group

\section{Students lead the learning process $\rightarrow$ Students build their} own knowledge and conceptual understandings

The effect of using inquiry on the development of conceptual thinking was mentioned by another teachers. "we have the luxury to introduce things.... anything that is related to the unit of inquiry or concept or to a skill.... doing that actually allows the kids to see things sometimes" HT3-Teachers' focus group

"I think that the inquiry, the conceptual understanding or the transdisplinary." - C - Leaders focus group

Students build their own knowledge and conceptual understandings $\rightarrow$ Students are able to Apply learning in real life situations

Conceptualizing ideas makes students see how those ideas can transfer encouraging them to apply ideas in different situations.

"students become confident when the students know the basic information and facts and have the knowledge and understand he can apply this in different situation because the concepts transfer these understanding into different situation." C - Leaders 
focus group

\section{Students are able to Apply learning in real life situations $\rightarrow$ Self-efficacy beliefs}

Taking action and linking what was learned in class to real life builds self-efficacy beliefs.

"students become confident when the students know the basic information and facts and have the knowledge and understand he can apply this in different situation because the concepts transfer these understanding into different situation." C - Leaders focus group

"connecting the things in the world together builds self confidence" HT3 - Teachers' focus group

\section{Students build Attitudes and Skills $\rightarrow$ Self-efficacy beliefs}

Parents highlighted how they can see the role of enhancing communication skills when presenting ideas contribute to students' self-confidence.

"She acquired some skills like presentation skills that made her more confident" P2 - Parents' focus group

"When he presents research, it gives him confidence" P3 - Parents' focus group

\section{Students are able to Apply learning in real life situations $\rightarrow$ Students Reflect on their actions that is a form of inquiry}

When students take actions, they reflect on their actions and are able to identify what went wrong, accept it, and decide how to overcome it. Teachers informed how this happens.

"she reconsidered and start to model in the right way." HT4 - Teachers' focus group

From the coordinator perspective it is always referring to the action cycle gives a change for overcoming any faults that consequently enhance self-efficacy beliefs.

"the actions cycle that we always refer back to stresses the idea that he made a choice and that he made an action and now he is reflecting and reconsidering his actions to make it better"- $C$ Leaders' focus group

\section{Students Reflect on their actions $\rightarrow$ Self-efficacy beliefs}

The ability to reflect and overcome mistakes promotes self-efficacy beliefs. The principle of the school saw that clearly with students.

"when the IB students make mistakes, they know that he did and they can reflect ...... is a very important thing that affect our students' believing in their abilities" - PR - Leaders' focus group

Teachers also informed about how when they are used to reflection, they reflect quickly and this affects self-efficacy beliefs. "they reflect automatically it takes them one minute and they return back to me and say; miss I did this and this is what I want to do" HTI - Teachers' focus group

\section{Specific aspects of School Culture:}

Stakeholders identified four aspects of the school culture that they believed supported students' self-efficacy beliefs; modeling the learners' profile, a stress free, trust and respect, and motivation. Stakeholders differed in their perspective of which of those is an aspect of school culture that affects students' self-efficacy beliefs.

\section{Model the Learners' profile}

From the leaders perspective, it is the culture that shapes how people deal together.

"I believe they reached this because of the common culture and the common way all teachers, parents, students themselves and the administration deal together" C - Leaders' focus group

Leaders are the ones who identified having a homogenous learning community where everybody is modeling the learners' profile contributes to supporting Students' self-efficacy beliefs.

"There is a homogenous learning community .... they embrace the system ......... modeling the learner's profile" C-Leaders'focus group

\section{Trust \& Respect}

Teachers saw that the school culture trusts students' abilities and respects their opinion them trust and respect promotes self-efficacy beliefs.

"I give them opportunities. I tell them go and find yourself, and when he finds it, he feels success and this boosts self-confidence, motivation encouragement, support and respect "HT3 - Teachers" focus group

"When they try a new idea that seems silly and they find the person in front of them respecting it, they feel that they can do something and they try more, so their abilities increase and they succeed" AT - Teachers' focus group

This was felt by student themselves;

"here so much respect, so much friends, most of the school are my friends, I play everything with them, they care for me and always respect me and like that." S3 - Students' focus group

and parents;

"the idea of respect and giving them love more than fear" P1 - Parents' focus group

\section{Stress Free}

From the students' perspective, the stress free environment that does not fear mistakes boosts them to 
have confidence to try again.

"even when we make mistakes, they don't shout, they

tell us try again” S5-Students' focus group

"we were like joking and having fun" S3-Students'

focus group

\section{Motivation}

Parents saw the motivational atmosphere is one of the aspects that boosts self confidence in students.

"the motivational atmosphere that is available at the school is seen in students" P1- Parents' focus group

\section{Research Question 3: How much do aspects, that lead to learners' self-efficacy beliefs from stakeholder's perspective, match components of the PYP?}

The following table is matching themes found from the data as reasons behind self-efficacy beliefs to accomplish PYP tasks to the IBPYP programme standards and practices (2014):

Table 3. Matching themes found as reasons behind self-efficacy beliefs to accomplish PYP tasks and the IBPYP programme standards and practices

\begin{tabular}{|c|c|}
\hline \multicolumn{2}{|r|}{ IBPYP Pedagogy: } \\
\hline Study Themes & IBPYP standards \& practices \\
\hline $\begin{array}{l}\text { Inquiry } \\
\text { Strategies }\end{array}$ & $\begin{array}{l}\text { Section A: Philosophy } \\
\text { The school is committed to a constructivist, inquiry-based approach to teaching and learning that promotes inquiry and } \\
\text { the development of critical-thinking skills. } \\
\text { Section C: Curriculum } \\
\text { The written curriculum provides opportunities for student learning that is significant, relevant, engaging and challenging. } \\
\text { Teaching and learning engages students as inquirers and thinkers. } \\
\text { The school ensures that inquiry is used across the curriculum and by all teachers. }\end{array}$ \\
\hline $\begin{array}{l}\text { Students } \\
\text { leading the } \\
\text { learning } \\
\text { process }\end{array}$ & $\begin{array}{l}\text { Section C: Curriculum } \\
\text { Teaching and learning supports students to become actively responsible for their own learning. } \\
\text { Teaching and learning develops student attitudes and skills that allow for meaningful student action in response to } \\
\text { students' own needs and the needs of others. } \\
\text { Teaching and learning empowers students to take self-initiated action as a result of the learning. }\end{array}$ \\
\hline $\begin{array}{l}\text { build } \\
\text { knowledge and } \\
\text { conceptual } \\
\text { understandings }\end{array}$ & $\begin{array}{l}\text { Section B: Organisation } \\
\text { The schedule or timetable allows for in-depth inquiry into the transdisciplinary and disciplinary dimensions of the } \\
\text { curriculum. } \\
\text { Section C: Curriculum } \\
\text { The written curriculum identifies the knowledge, concepts, skills and attitudes to be developed over time. } \\
\text { The school has scope and sequence documents that indicate the development of conceptual understanding, knowledge } \\
\text { and skills for each PYP subject area. }\end{array}$ \\
\hline $\begin{array}{l}\text { Application in } \\
\text { real life } \\
\text { situations }\end{array}$ & $\begin{array}{l}\text { Section A: Philosophy } \\
\text { The school promotes responsible action within and beyond the school community. } \\
\text { Section C: Curriculum } \\
\text { The written curriculum allows for meaningful student action in response to students' own needs and the needs of others. } \\
\text { Teaching and learning develops student attitudes and skills that allow for meaningful student action in response to } \\
\text { students' own needs and the needs of others. }\end{array}$ \\
\hline $\begin{array}{l}\text { Students' } \\
\text { Attitudes and } \\
\text { Skills }\end{array}$ & $\begin{array}{l}\text { Section C: Curriculum } \\
\text { The written curriculum identifies the knowledge, concepts, skills and attitudes to be developed over time. } \\
\text { Teaching and learning addresses the competencies, experiences, learning needs and styles of students. }\end{array}$ \\
\hline Reflection & $\begin{array}{l}\text { Section C: Curriculum } \\
\text { The written curriculum provides opportunities for reflection on human commonality, diversity and multiple perspectives. } \\
\text { Teaching and learning engages students in reflecting on how, what and why they are learning. }\end{array}$ \\
\hline \multicolumn{2}{|r|}{ School Culture: } \\
\hline Study Themes & IB standards \& practices \\
\hline Modeling LP & $\begin{array}{l}\text { Section B: Organisation } \\
\begin{array}{c}\text { The head of school/school principal and programme coordinator demonstrate pedagogical leadership aligned with the } \\
\text { philosophy of the programme(s). } \\
\text { Section C: Curriculum }\end{array} \\
\text { Collaborative planning and reflection addresses the IB learner profile attributes. } \\
\text { The written curriculum fosters development of the IB learner profile attributes. } \\
\text { Teaching and learning develops the IB learner profile attributes. } \\
\text { Student learning and development related to all attributes of the IB learner profile are assessed and reported. }\end{array}$ \\
\hline Trust/respect & $\begin{array}{c}\text { Section A: Philosophy } \\
\text { The school promotes open communication based on understanding and respect. } \\
\text { Section C: Curriculum } \\
\text { Teaching and learning fosters a stimulating learning environment based on understanding and respect. } \\
\text { Teaching and learning empowers students to take self-initiated action as a result of the learning. }\end{array}$ \\
\hline Stress Free & $\begin{array}{l}\text { Section C: Curriculum } \\
\text { The school provides students with feedback to inform and improve their learning. } \\
\text { The school provides environments in which students work both independently and collaboratively. } \\
\text { Teaching and learning encourages students to demonstrate their learning in a variety of way }\end{array}$ \\
\hline Motivating & $\begin{array}{l}\text { Section C: Curriculum } \\
\text { and learning fosters a stimulating learning environment based on understanding and respect. }\end{array}$ \\
\hline
\end{tabular}




\section{Discussion}

This study was exploring the impact of implementing PYP on students' self-efficacy beliefs. The exploration identified specific aspects in pedagogy and school culture that lead to students' self-efficacy beliefs. Moreover, the study resulted in interpreting a spiral of different aspects of pedagogy affecting self-efficacy beliefs supported by specific aspects in the school culture. The model in Figure (1) presents a way of looking at the relationships between aspects found and their impact on students' self-efficacy beliefs.

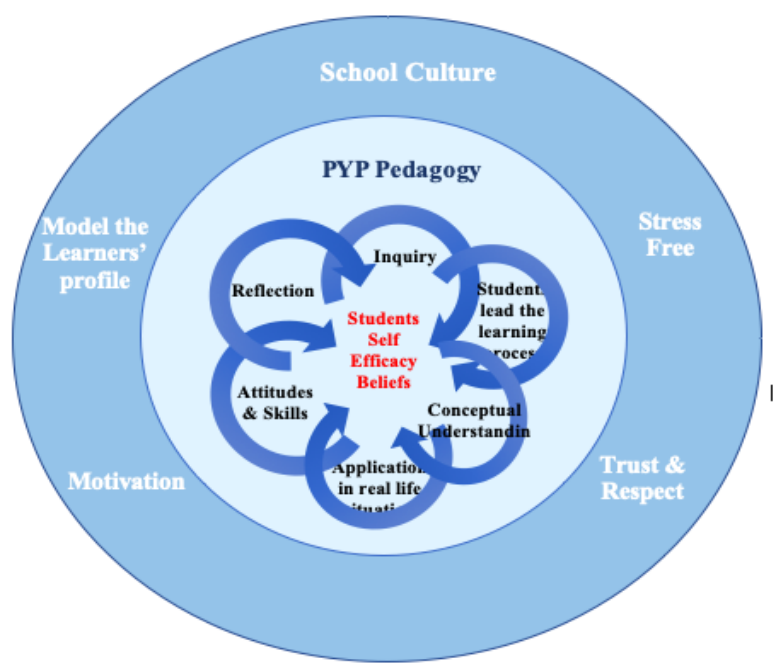

Figure 1. Aspects of school culture and aspects of PYP pedagogy affecting students' self-efficacy beliefs

The figure shows self-efficacy in the middle affected by specific aspects of PYP pedagogy relating and integrating, that can, but not necessary go through this order; Inquiry Strategies $\rightarrow$ Students lead the learning process $\rightarrow$ Conceptual understandings $\rightarrow$ Application in real life situations $\rightarrow$ Students build Attitudes and Skills $\rightarrow$ Students Reflect on their actions. The spiral is supported to continue by the surrounding school culture that has specific aspects of; stress free, trust and respect, motivation, and adults modeling the learners' profile attribute.

Reference [31] sees that, "Sources of self-efficacy may be personal and reside within people, or result from their social and physical environments." (P.87). This was also supported by [34] based on basic assumptions of social cognitive theory that self-efficacy is developed by two factors interaction. The first is the capacity of understanding cause and effect relations, self-observations and self-reflection. The second is the responsiveness of environments to the child's actions [34]. Reference [11] recommended principles that lead to officious students in PYP schools; create learning environments that encourages students take ownership of their learning, provide opportunities for reflection, encourage collaboration, use authentic tasks and problems, scaffold and support students' learning, create a culture of learning and respect for others.
The discussion of findings will first discuss the PYP pedagogy and how they relate and integrate to affect the students' self-efficacy beliefs. Second it will discuss how aspects of school culture can support students' self-efficacy beliefs and enhance them.

\section{PYP Pedagogy:}

Aspects of PYP pedagogy are interrelated, there implementation form holistic education. According to the IB document Making the PYP Happen [32], the word 'holistic' can describe the PYP curriculum model that presents the essential elements as a whole. According to [32], "the curriculum as a whole; the transdisciplinary themes and subject areas as aspects of a whole; and the school community as a whole." (p.60), represented in the following figure:

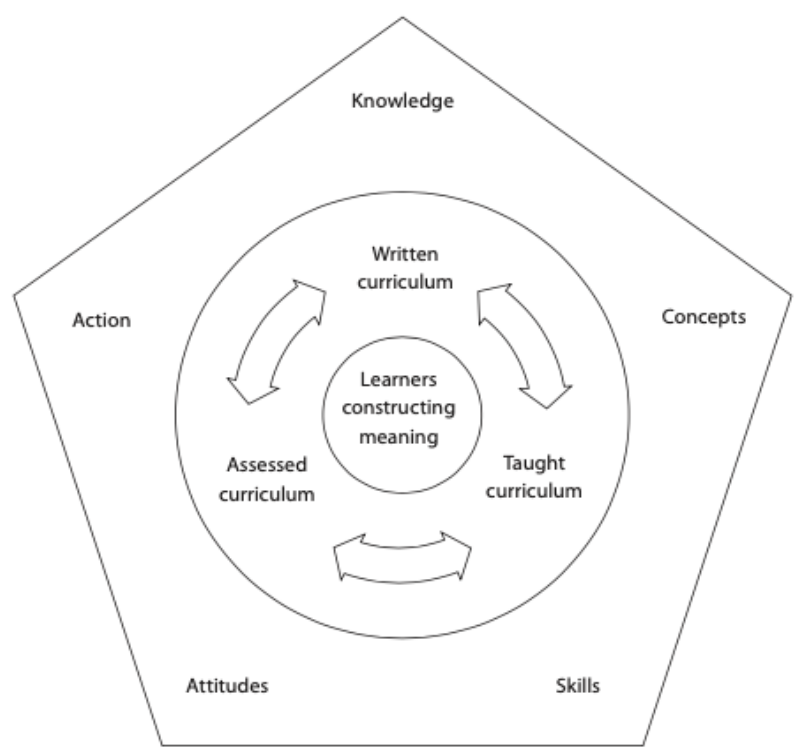

(International Baccalaureate Organization [32], figure 20, p.60)

The study findings indicated that aspects of pedagogy affecting self-efficacy can affect self-efficacy directly, as well as affecting each other forming a spiral that can, but not necessary, go in the following order;

Students use Inquiry Strategies $\rightarrow$ Students lead the learning process $\rightarrow$ Students build their own knowledge and conceptual understandings $\rightarrow$ Students are able to Apply learning in real life situations $\rightarrow$ Students build Attitudes and Skills $\rightarrow$ Students Reflect on their actions

Inquiry is an integral part of the PYP programme. One of the practices required by the IBPYP is; "The school is committed to a constructivist, inquiry-based approach to teaching and learning that promotes inquiry and the development of critical-thinking skills." [33]. Reference [10] concluded that using the inquiry model increase students' self-efficacy beliefs.

Reference [3] identifies mastery experiences to be one of the sources of self-efficacy beliefs. However, [29] argues that mastery experience should be authentic, i.e. it is real 
and unique, not created and biased. Holistic learning through PYP pedagogy can initiate authentic mastery experiences as a source of self-efficacy beliefs. According to IBPYP guide [32], the PYP encourages teachers to give students "opportunities to test and revise their models, to allow them to make connections between their previous and current perceptions, to allow them the freedom to construct their own meaning." (P.29). This is achieved through using inquiry strategies and cycles linking new knowledge to existing knowledge and repeating the cycle until mastery of content is reached.

Inquiry is based on students exploring different resources and processing their own path to learning using critical thinking. According to [12], "Students focused on mastery experiences will most likely practice more critical thinking and processing strategies as well as be more resourceful. (P.16). In addition, the freedom to construct their own meaning in steps gives a chance for students to achieve and minimizes the chances for failure. Reference [37] sees that, "Mastery (successful performance) can lead to a high level of perceived self-efficacy, while experiences of failure lower self-efficacy and impede one's behaviour" (p.3). As [5] puts it;

Successes build a robust belief in one's efficacy. Failures undermine it. If people have only easy successes they are readily discouraged by failure. Development of a resilient sense of efficacy requires experience in overcoming obstacles through perseverant effort. Resilience is also cultivated by learning how to manage failure so it is informative rather than demoralizing" (p. 22).

According to [12], "Mastery experiences, are the most effective at building a strong sense of efficacy because it builds off of successes" (p.14). The PYP guide mentions "PYP schools ensure that the learning is engaging, relevant, challenging and significant." (P.5). Reference [12] sees that personal challenges keep the individual motivated in order to manage educational development. Mastery experiences help form self-efficacy perceptions when individuals judge the effects of their actions and their interpretations assist in developing efficacy beliefs [29]. This means that although mastery experience is a cause of self-efficacy beliefs, self-efficacy beliefs lead to mastery experiences. Self- efficacy beliefs play a causal role in students' development and use of academic competencies [15].

When students master what they are doing their skills develop. Reference [3] sees that, "Through guided mastery we cultivated competences, coping skills, and self-beliefs that enabled people to exercise control over their perceived threats" (p.22-23). Skillful students are more officious. Reference [9] concluded that good communication skills are significantly correlated with improved social self-efficacy.

\section{School Culture:}

Reference [3] highlighted the role of the culture in building self-efficacy beliefs by identifying experiences provided by social models and social persuasion as sources of self-efficacy beliefs. Reference [21] concluded that modeling specific self-regulatory techniques, describing their form, and providing enactive feedback regarding their impact facilitate improvements in perceived efficacy.

Social modeling or vicarious learning was seen by [31] as learning that takes place through observation and social engagement without direct experience. The IB document Making the PYP Happen [32] in its guide for implementing the PYP mentions that; "effective action should be modelled by the adults in the school community" (p.26). The PYP depend in its inquiry on the behavior modeled by adults in their environment [32].

Reference [6] clarified that learning in the form of modeling is not limited to imitation. He also clarified that it does not stop creativity as exposure to different models encourage selectivity and encourage students to "adopt advantageous elements, improve upon them, synthesize them into new forms, and tailor them to their particular circumstances" (p.13-14). Reference [12] highlighted that people are naturally selective of the information they gather and how it influences them. Reference [30] saw that culture affect self-efficacy by the information it provides and how it is incorporated into self-efficacy judgments.

Social persuasion as a source of self-efficacy beliefs is seen by [23] as providing specific and credible feedback that indicates how the performance has improved. Just praising work does not lead to efficacy unless students understand which aspect of the performance is good. He also sees what he identifies as 'attributional feedback' as a persuasive source of self-efficacy. Attributional feedback is feedbacking that links outcomes to specific attributes [22].

Self-efficacy is mostly affected by the teachers' evaluations and feedback [30]. According to [19];

"During a child's formative period, teachers serve as important contributors to the formation of a child's intellectual efficacy. Children's appraisals of their capabilities are heavily affected by the way teachers evaluate their performances and help them to develop self-regulatory skills in managing learning activities." (p.88)

Not only teachers, but homes, neighborhood, communities, classrooms, and schools create a feeling of collective efficacy defined by [29] as "a group's shared belief in its capability to attain its goals and accomplish desired tasks" (p. 362).

Reference [12] emphasis the role low power cultures where open, creative learning experiences are promoted and students are provided with chances for independent leadership roles. These cultures promote self-efficacy beliefs. Reference [12] sees that, "Enhancing self- efficacy emotionally and physically can be done by working to reduce stress and negative emotions" (P.18). According to 
[36], "Teaching styles which are authoritarian and controlling produce students with low self-efficacy who tend to lose initiative and learn less effectively than students whose teachers are more authoritative and supportive of autonomy and self-regulation" (p.31). Classroom environments that promote autonomy, mastery and purpose increase intrinsic motivation and improve self-efficacy [24].

\section{Conclusions}

This study elaborates on our understanding of how PYP schools support the development of students' self-efficacy beliefs. Self-efficacy beliefs are built and enhanced by initiating and maintaining a culture that supports specific aspects of pedagogy gradually reaching the student. The PYP holistic model that approaches the child as a whole promotes those aspects as well as build the culture that supports it.

Inquiry can be highlighted as the beginning of a cycle that drives other aspects of pedagogy resulting in students' self-efficacy beliefs. Other aspects of PYP pedagogy move this cycle. Releasing power and providing students with a chance to lead the learning process, build their own conceptual understandings, take the action they choose, and finally reflect on their actions, result in authentic mastery experiences that build self-efficacy beliefs. Consequently, self-officious students are more likely to reach mastery experiences and the cycle goes on.

A school culture that is built on understanding and respecting create social models that give a chance for students to learn through observation and social engagement. The school culture also contributes to building self-efficacy beliefs by giving positive specific feedback highlighting to students what exactly is good about their performance and supporting their growth journey.

Self-efficacy cannot be seen on its own. It is related to other aspects of self-regulation, intrinsic motivation, and self-concept. However, it can be a starting point to enhance other self-belief notions.

\section{Appendix 1: Information Sheets and Consent Forms for Different Stakeholders}

\author{
Permission from School Leaders \\ Background Information
}

Title: The Impact of Implementing the IB PYP on Students' Self-Efficacy Beliefs

You school is being invited to take part in a research project titled; The Impact of Implementing the IB PYP on
Students' Self-Efficacy. Before you decide on whether to take part, it is important for you to understand why the research is being done and what it will involve. This information sheet will give you information about the research to decide if you will wish to take part.

\section{Purpose of the research}

The purpose of this study will be to explore the impact of implementing the Primary Years Program (PYP) on self-efficacy in PYP schools in Egypt.

\section{Why have my school been chosen?}

A group of teachers, leaders, parents and students from a PYP school in Egypt is to be chosen randomly to participate in the study. Teachers, leaders, parents and students volunteer to participate in the study. Each group is interviewed alone in a focus group set-up.

\section{Does the school have to take part?}

Taking part in the research is completely voluntarily. If you do decide to take part you will be given this information sheet to keep (and be asked to sign a consent form). You can still withdraw if you do not want to be part of the study.

What do teachers, students, leaders and parents have to do? / What will happen to them if they take part?

The whole process will take $30-40 \mathrm{~min}$ from each group of; teachers, parents, students and leaders participating in a focus group discussion where they will be asked to reflect on their experience with inquiry being implemented; benefits, drawbacks, takeaways, limitations, ...etc.

\section{What are the possible inconveniences taking part?}

A selection of the school's teachers, leaders, parents and students will participate in a $30-40 \mathrm{~min}$ in a focus group discussion where they will be asked some questions about their observations, ideas and opinions giving examples.

\section{What are the possible benefits of taking part?}

- Teachers, leaders, students and parents will be asked to be opened about their personal experience, feelings and ideas.

- Teachers, leaders, students and parents will dedicate sometime for the interviews.

Will my taking part in this project be kept confidential?/What will happen to the results of the research project?

Data from the research will be published, but the school 
and participants' names will not be identified in any reports or publications.

\section{Thank you for taking the time to read this information sheet.}

Please contact if you have any other queries or clarifications.

Researchers: Nevine El Souefi - Date: 19/4/2018

\section{Consent form: School Leaders}

\section{Title: The Impact of Implementing the IB PYP on Students' Self-Efficacy}

\section{Researchers: Nevine El Souefi}

\section{Details of Participation:}

1. Teachers, leaders, students and parents participating each in a focus group discussion for around 40 minutes.

2. Teachers are observed while teaching in the class.

3. Review of students work and unit plans.

\section{Permission Statement}

1. I understand that our teachers', leaders', parents' and students' participation is voluntary and that they can withdraw unconditionally at any time from taking part in this study.

2. I have been informed about the study with the attached information sheet.

3. I understand that the coded data may be shared with other competent researchers. Our school name and other identifying details will not be shared with anyone.

4. The overall findings may be submitted for publication in a scientific journal, or presented at scientific conferences.

We are giving our permission for data to be used for the outlined purposes of the present study. All questions that we have about the research have been satisfactorily answered.

Signature:

Date:

\section{REFERENCES}

[1] A. Bandura. Self-efficacy: Toward a unifying theory of behavioral change, Psychological Review, 84, 191-215, 1977.
[2] A. Bandura. Social foundation of thought and action: A social cognitive theory, Englewood Cliffs, NJ: Prentice-Hall, 1986.

[3] A. Bandura. Self-Efficacy: The Power of Believing You Can, In V. S. Ramachaudran (Ed.), Encyclopedia of human behavior (Vol. 4, pp. 71-81), New York: Academic Press, 1994.

[4] A. Bandura. Self-efficacy: The exercise of control, New York: Freeman, 1997.

[5] A. Bandura. Swimming against the mainstream: the early years from chilly tributary to transformative mainstream, Behaviour Research and Therapy (42), 613-630, 2004.

[6] A. Bandura. Self-efficacy beliefs for adolescence, 307-337, Information Age Publishing, 2005.

[7] A. Bandura. Guide for constructing self-efficacy scales, In F. Pajares \& T. Urdan (Eds.), Self-efficacy beliefs of adolescents (pp. 307-337). Greenwich, CT: Information Age Publishing, 2006.

[8] A. Bryman. Social research Methods. $4^{\text {th }}$ Edition, New York. Oxford University Press, 2012.

[9] A. Erozkan, A. The effect of communication skills and interpersonal problem solving skills on social efficacy, Educational Sciences: Theory and Practice, 13(2), 739-745, 2013.

[10] A. Featonby, A. The Use of the 'Teaching as Inquiry Model' to Develop Students' Self-efficacy in Literature Response Essay Writing, Kairaranga - Weaving educational threads. Weaving educational practice. Volume 13, ISSUE 1, 2012.

[11] A. Kitsantas and A. Miller. Characteristics and Context of Primary Years Program (PYP) Students' Self-Efficacy and Self-Regulatory Development, George Mason University, 2015.

[12] A. Koehler. Raising awareness of self-efficacy through self-regulated learning strategies for reaching is secondary ESL classroom, Hamline University, 2007.

[13] A. Lane, L. Jones, M. Stevens. Coping with Faliour: The effects of self=esteem and coping on changes in self-efficacy. Retrieved on 7/2/2021 from https://www.researchgate.net/p ublication/285194018_Coping_with failure The effects o f_self-esteem_and_coping_on_changes_in_self-efficacy, 2001 .

[14] B. Zimmerman. Developing self-fullfilling cycles of academic regulation: An analysis of exemplary instructional models, The Guilford Press, 1998.

[15] B. Zimmerman. Attaining self-regulation: A social cognitive perspective, In M. Boekaerts, P. R. Pintrich, \& M. Zeidner (Eds.), Handbook of self-regulation (pp. 13-39). New York: Academic, 2000.

[16] B. Zimmerman, S. Bonner, and R. Kovach. Developing self-regulated learners: Beyond achievement to self-efficacy, Washington D.C., Ameri, 2006.

[17] J. Lane, A. Lane, A. Kyprianou. Self-Efficacy, Self-Esteem and Their Impact on Academic Performance, Social behavior and phychology, 32(3),247-256, 2004.

[18] C. Lau'A. Kitsantas' A. Miller' E. Rodgers. Perceived 
responsibility for learning, self-efficacy, and sources of selfefficacy in mathematics: a study of international baccalaureate primary years programme students, Social Psychology of Education, 21:603-620, 2018.

[19] C. Pastorelli, G. Caprara, C. Barbaranelli, J. Rola, S. Rozsa, A. Bandura. The Structure of Children's Perceived Self-Efficacy: A Cross-National Study, European Journal of Psychological Assessment, Vol. 17, Issue 2, pp. 87-97, 2001.

[20] C. Wang and S. Pape. Self-efficacy beliefs and self-regulated learning strategies in learning English as a second language: Four case studies, CATESOL, 16, 1-19, 2004.

[21] D. Schunk. Modeling and attributional effects on children's achievement; A self-efficacy analysis, Journal of Educational Psychology, 73,93-105, 1981.

[22] D. Schunk. Self-efficacy and achievement behaviors, Educational Psychology Review, 1, 173-208, 1989.

[23] D. Schunk. Self-efficacy, motivation, and performance, Journal of Applied Sport Psychology, 7(2), 112-137, 1995.

[24] E. Deci, R. Koestner, \& R. Ryan. A meta-analytic review of experiments examining the effects of extrinsic rewards on intrinsic motivation, Psychological Bulletin, 125, 692-700, 1990.

[25] E. Madriz. Focus groups in feminist research. In: N. Denzin and Y. Lincoln, eds. Handbook of qualitative research, Thousand Oaks, CA: Sage, 835 850, 2003.

[26] E. Skop. The methodological potential of focus groups in population geography, Population, space and place, 12 (2), 113 124, 2006.

[27] F. Pajares and D. Schunk. Self-beliefs and school success: Self-efficacy, self- concept, and school achievement, Self Perception, 239-265, 2001.

[28] F. Pajares. Overview of social cognitive theory and of self-efficacy, 2002. Retrieved January 4, 2007, from http://www.emory.edu/EDUCATION/mfp/eff.html

[29] F. Pajares. Self-efficacy during childhood and adolescence, In F. Pajares \& T. Urdan (Eds.). Self-efficacy beliefs of adolescents (339-367), Greenwich, CT: Information Age Publishing, 2006.

[30] G. Oettingen. Cross-cultural perspective on self-efficacy, In A. Bandura (Ed.), Self-efficacy in changing societies (pp. 149-176), New York: Cambridge University Press, 1995.

[31] G. Tuchten. Concept development for facilitating the health and safety efficacy of South African mine workers,
University of Pretoria, 2011

[32] International Baccalaureate Organisation. Making the PYP happen: A curriculum framework for international primary curriculum, 2007, 2009.

[33] International Baccalaureate Organization. IB Standards and practices, 2014.

[34] J. Maddux. Self-Efficacy: The Power of Believing You Can, The Oxford Handbook of Positive Psychology (2nd edn) Edited by Shane J. Lopez and C.R. Snyder, 2012.

[35] L. Ching. Strategy and self-regulation instruction as contributors to improving students' cognitive model in an ESL program, English for Specific Purposes, 21, 261-289, 2002.

[36] L. King. ATL in the IB Diploma, A Literature Review of the Key Skills of Effective Learning, 2013.

[37] M. Kear. Concept Analysis of Self-Efficacy, Graduate Research in Nursing, 1-7, 2000.

[38] M. Mone, D. Baker, F. Jeffries. Predictive validity and time dependency of self-efficacy, self-esteem, personal goals, and academic performance, Educational and Psychological measurement, Sage publication, Vol. 55 No. 5, 1995.

[39] P. Dodgson and J. Wood. Self-esteem and the cognitive accessibility of strengths and weaknesses after failure, Journal of Personality and Social Psychology, 75, 178-197, 1998.

[40] P. Pintrich \& E. De Groot. Motivational and self-regulated learning component of classroom academic performance, Journal of Educational Psychology, 82, 33-40, 1990. f, CCh2il0d0r1enH'osgPrerfece\&iveHdubSerlfP-

[41] R. Anthony, R. Jr. Artino. Self-Efficacy Beliefs: From Educational Theory to Instructional Practice, University of Connecticut, 2006.

[42] R. Barbour. Introducing qualitative research: A student guide to the craft of doing qualitative research, London: Sage Publications, 2008.

[43] R. Bogdan and S. Biklen. Qualitative Research for Education: An Introduction to Theories and Methods, Boston: Pearson Education Group, Inc, 2003.

[44] R. Schwarzer and M. Jerusalem. Generalized Self-Efficacy scale, In J. Weinman, S. Wright, \& M. Johnston, Measures in health psychology: A user's portfolio, Causal and control beliefs (pp. 35-37). Windsor, UK: NFER-NELSON, 1995.

[45] V. Braun, and V. Clarke. Using thematic analysis in psychology, Qualitative Research in Psychology, 3 (2). pp. 77-101. ISSN 1478-0887, 2006. 